\title{
A POBREZA E EXCLUSÃO COMO CONSEQUENCIA E FACTOR DE VIOLÊNCIA
}

\author{
MARIA JOAQUINA RUAS MADEIRA
}

Lisboa. Portugal.

Quando eu nasci Tudo quanto era preciso para salvar o mundo Já estava descoberto Só faltava uma coisa Salvar o mundo

Almada Negreiros

\section{POBREZA E EXCLUSÃO SOCIAL NA EUROPA E NO MUNDO.}

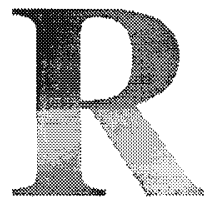

econhece-se hoje que os fenómenos da Pobreza e da Exclusão radicam, se assim se pode dizer, na própria forma de organização das Sociedades. Desde sempre se verificou a desigual distribuição de rendimentos e sociedades, uma vez que a estratificação social transforma as desigualdades de classe em desigualdades sociais.

A desigualdade social resulta pois da não equidade no acesso a bens, serviços ou oportunidades.

\subsection{Do crescimento económico ao desenvolvimento territorial.}

A existência de um momento de prosperidade e crescimento económico das sociedades modernas, com início no final da II Guerra, levou à crença de que haveria uma continuidade e sustentabilidade do crescimento, através do igual acesso das populações ao mercado, aos serviços e aos factores de produção. De tal forma que esta prosperidade se estenderia aos países do terceiro mundo e solucionaria os problemas que, nas sociedades desenvolvidas, levavam alguns sectores da população a situações de exclusão e do próprio exercício da cidadania. Generaliza-se a crença de que o crescimento económico era sinónimo de inclusão.

Assim, a justiça social seria alcançada nos países periféricos em modernização, quer pelo benefício de salários e outros rendimentos 
(trabalho), quer através de apoios estatais nos casos de impossibilidade de trabalhar (rendimentos garantidos pela segurança social).

"A realização da justiça social implica a satisfação das necessidades humanas fundamentais e uma distribuição equitativa dos recursos materiais. Visa o acesso universal aos serviços essenciais nas áreas da saúde e da educação, a igualdade de oportunidades logo à partida, a proteç̧ão das pessoas ou dos grupos mais desfavorecidos, e alguma moderação nas áreas da retribuição, do consumo e do lucro." (Direitos humanos e serviço social; 33).

Mas, este paradigma industrial de desenvolvimento começa a decair na década de 70, com a crise económica provocada pelas crises petrolíferas. Também os avanços tecnológicos originaram uma crise estrutural do próprio modelo de economia industrial dominante. Situações como salários em atraso, falências, reformas antecipadas e desemprego foram comuns neste período. As crises constantes acompanhadas de recuperações e novas crises deram descrédito ao pensamento de que a prosperidade inevitável de todos os membros das sociedades era enganador. Isto porque o terceiro mundo se continuava a debater com o problema da fome, e o mundo moderno mostrava índices de pobreza alarmantes.

$\mathrm{Na}$ Europa, os conturbados anos 70 evidenciaram uma recusa do poder político em aceitar a presença da pobreza e o seu aumento. Um dos pressupostos do modelo de crescimento económico era o de que as desigualdades sociais se superariam com a igualdade de acesso da população aos recursos gerados por esse mesmo crescimento. Politicamente aceitar a ideia de que o modelo de crescimento económico, e a própria organização da sociedade não era totalmente justa e possuía grupos em situação de desfavorecimento extremo, tornava-se difícil uma vez que desta constatação transparecia um problema de índole social.

É nos finais dos anos 70 que a gravidade crescente dos problemas sociais vem revelar os limites do modelo de crescimento económico. Reconhece-se que "os pobres" existem em todos os países e põem-se em prática programas de combate ao fenómeno da pobreza. Em termos Europeus obtiveram a designação de Programas Europeus de Luta Contra a Pobreza (I Programa de Luta Contra a Pobreza Europeu, 1975-1980).

A década de 90 continua a ser caracterizada pelas mesmas preocupações, sendo feita a introdução da ideia de pobreza humana, a qual pretende centrar a tónica do desenvolvimento territorial, que deve ser encarado enquanto um processo que melhora de forma durável e continuada a qualidade de vida da população, através não só da eficácia económica, mas também da equidade social, da 
solidariedade, da qualidade ambiental, da responsabilidade cívica $e$ da participação democrática.

A tónica é acentuada nos projectos locais de luta contra fenómenos de pobreza e exclusão.

Se é um facto que há um progresso em termos de desenvolvimento humano, nos últimos trinta anos, também o é a constatação da persistência de níveis inaceitáveis de privação por parte de alguns cidadãos que ainda assim se vêm privados de determinados bens. Poderia até dizer-se que face ao quadro actual, se verificou um aumento das desigualdades.

\subsection{Quais os factores de risco que podem estar na origem da po- breza?}

Pode afirmar-se que "o fenómeno da pobreza situa-se sempre num determinado contexto político, económico e social e é a resultante da interacção entre variáveis que relevam de cada um desses domínios. Por isso, procurar soluções para o problema da pobreza implica a consideração das transformações a operar no sistema socio-económico para que possam alterar-se as causas geradoras da pobreza e não apenas as suas manifestações mais visíveis." (Costa, A.B., 1985).

A pobreza pode assentar em factores de ordem económica e distributiva:

1. Na escassez de recursos absoluta relacionada com a população, ou seja, dado que a relação entre a população total e os recursos que são explorados é discrepante, mesmo que se verificasse a equidade na distribuição, a pobreza não iria ser ultrapassada.

2. No potencial de recursos existente, ou seja, se existir uma insuficiência em termos de desenvolvimento económico para a rentabilização do sistema produtivo, será necessário, no que diz respeito às estratégias de desenvolvimento, valorizar o crescimento económico mas em simultâneo priorizar a produção de bens que vão ao encontro da satisfação das necessidades básicas (criação de emprego, modernização do trabalho agrícola, criação de equipamentos colectivos para o bens estar das comunidades). Tratase de fomentar nos programas de desenvolvimento objectivos concretos para a melhoria das condições de vida dos grupos mais desfavorecidos.

3. No desenvolvimento económico com desigual repartição da riqueza, o mesmo quer dizer alguns mecanismos de distribuição geram o fenómeno da pobreza, quer no que diz respeito aos salários, quer aos impostos e subsídios. 
Os novos factores de risco, no entanto, estão associados às novas transformações sociais em curso. De entre estas transformações contam-se:

- Mutações no mercado de trabalho em consequência da globalização e do rápido crescimento da sociedade baseada no conhecimento, nas tecnologias de informação e da comunicação.

- Um contexto demográfico com mais pessoas a viverem mais tempo.

- Taxas de natalidade em queda.

- Uma tendência mais acentuada para uma maior diversidade étnica, cultural e religiosa, em virtude do aumento dos fluxos migratórios.

- Mudanças nas estruturas familiares, com índices crescentes de situações de ruptura.

- Desinstitualização da vida familiar acompanhada de mudanças nos papeis tradicionalmente atribuídos a homens e mulheres.

\subsection{Serão os modelos de crescimento económico e de globalização uma ameaça à coesão social?}

Entendendo este modelo de desenvolvimento como um processo de mudança de uma determinada sociedade em termos de eficácia económica e justiça social, evidencia-se o pressuposto que este deve ter em conta a satisfação das necessidades de várias ordem. Em suma este modelo consideraria as necessidades e melhoraria a existência humana. Seria ideal que tal assim fosse, mas na realidade e, dada a existência de desigual acesso aos bens, verificamos que o desenvolvimento económico não está a ser acompanhado de desenvolvimento social e cultural, o que potência uma resposta negativa por parte dos que se encontram privados do lucro do progresso.

A globalização, tal como ainda a conhecemos hoje, está relacionada com o desenvolvimento de relações económicas a nível mundial. Este tipo de globalização meramente económica e financeira exclui os indivíduos, grupos, regiões e países que não conseguem acompanhar as suas "exigências de competitividade" e os seus "níveis de produtividade".

Quer o desenvolvimento baseado no crescimento económico, quer esta globalização arriscam colocar em causa princípios fundamentais da humanidade como é o caso da cidadania. Não que este direito não seja defendido pela classe política mas porque as situações de privação ao nível social, económico e político levam os actores sociais a um desenraízamento da sociedade e perda de identidade com esta. Consequentemente, o exercício da cidadania está comprometido, uma 
vez que os indivíduos se sentem excluídos da própria sociedade.

A questão da injustiça social, fundada na questão dos recursos e no desigual acesso por parte dos socialmente desfavorecidos, possui factores de ordem pessoal e social, os quais se prendem com a existência de sistemas económicos e sociais provocadores de disparidades e com o círculo vicioso da pobreza.

Aliás, o Fórum Social de Porto Alegre foi o símbolo e a representação dos que procuram ter esperança, vindos dos diferentes locais do mundo que acreditam poderem partilhar algo e construir futuros mais solidários. "Um outro mundo é possível..." foi a "bandeira", referindo-se à possibilidade de uma alternativa realista ao processo de mundialização, que empurra $80 \%$ da população mundial a viver sem as condições básicas para enriquecer os restantes $20 \%$.

O que é facto é que ambos os fenómenos abordados, crescimento $e$ modelo de desenvolvimento e globalização, na base da competitividade constituem uma ameaça real à coesão social, tendência esta que urge modificar pois só assim poderá ser compreendida a questão dos conflitos sociais.

Mas a estes fenómenos liga-se também a crescente violência que se vem instalando nas sociedades, concluir-se-á que esta (violência) se trata de uma resposta pela negativa, por parte dos mais desfavorecidos.

No entanto, e para melhor compreensão desta problemática, será feita uma abordagem dos conceitos da exclusão e pobreza com vista ao seu encadeamento no próprio conceito de violência.

\section{POBREZA E EXCLUSÃO SOCIAL: O QUE SÃO?}

2.1. Da evolução do conceito de pobreza ao conceito de exclusão social.

A pobreza foi durante muitos anos o conceito encontrado para definir os mais desfavorecidos economicamente. No entanto as situações de pobreza foram-se diversificando, e sentiu-se a necessidade de criar novos conceitos para definir estas novas formas de pobreza, que se verificavam não só a nível económico, mas também a nível social e cultural.

Esta nova forma de ser pobre está ligada a um sentimento de revolta de quem teve uma situação estável e passa a sofrer dificuldades. Não possui dinheiro, é marginalizado pela sociedade e culturalmente renegado para segundo plano. Não querendo viver esta situação, esconde as suas dificuldades e sofre sem apoio, por vezes até dos familiares mais próximos. 


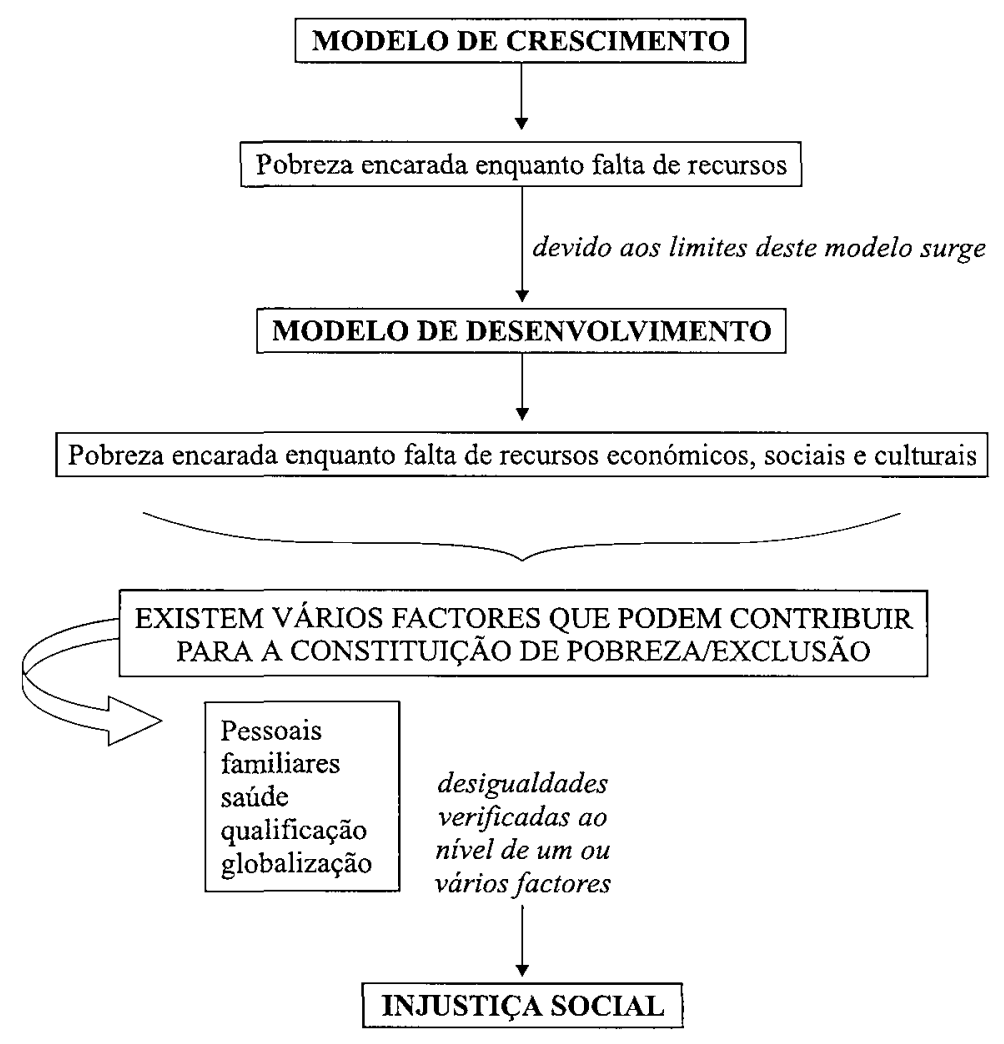

Embora o conceito de pobreza se tenha desenvolvido nas suas várias vertentes já há alguns anos, o de exclusão social é relativamente recente, e de interpretação variada. É devido a este facto que considerámos pertinente encontrar uma definição destes dois conceitos.

A pobreza é encarada como uma das dimensões da exclusão social e, foi durante muito tempo o conceito utilizado para definir situações de défice de recursos. Mas, desde finais dos anos 80 que o conceito de pobreza vem sendo substituído pelo conceito de exclusão social, visto ter-se necessidade de acentuar aspectos mais complexos do que as meras condições económicas de vida.

No entanto houve uma evolução do conceito de pobreza, desmultiplicando o conceito em várias dimensões que procuram enquadrar novas realidades associadas à pobreza. Surgem então dicotomias no conceito que nos dão conta de uma multiplicidade de significados que pode assumir: pobreza relativa/absoluta, pobreza objectiva/subjectiva, pobreza tradicional/nova pobreza.

O conceito de exclusão social enquadra algumas destas dimensões 
da evolução do conceito de pobreza. A pobreza é concebida como um dos fenómenos integrantes da exclusão social, embora a exclusão abranja formas de privação não material. A exclusão social enquanto conceito enquadra situações de ausência ou insuficiência de recursos sociais, políticos, culturais e psicológicos.

Contudo, os fenómenos da pobreza e da exclusão divergem entre si. A pobreza é um processo estático, enquanto que a exclusão é um processo dinâmico, que se encontra associado a uma acumulação de vários handicaps (carências habitacionais, rupturas familiares, isolamento social, etc.).

Qualquer forma de estruturação social tem inerente desigualdades e, torna-se legítimo expectar diferentes capacidades de articulação e acumulação dos vários tipos de recursos (sociais e materiais) por parte dos cidadãos que pertencem a essa sociedade.

A exclusão irá surgir com o agravamento dessas desigualdades, lançando assim uma oposição entre os cidadãos que mobilizam os seus recursos no sentido de uma plena participação social e os actores que, por falta desses recursos, se encontram vedados a fazê-lo. A exclusão resulta, deste modo, de uma desarticulação entre as diferentes partes da sociedade, originando para um conjunto de indivíduos uma falta de participação de um mínimo de benefícios que definem um membro de pleno direito dessa sociedade, opondo-se a um outro conjunto de indivíduos que goza de uma plena integração social nessa mesma sociedade.

A exclusão é encarada como umfenómeno multidimencional, como um conjunto de fenómenos sociais interligados que contribuem para a produção de excluídos. Coexistem a este nível fenómenos sociais diferenciados, como o desemprego, a pobreza, a discriminação, entre outros. E, devido ao facto da exclusão ter um carácter cumulativo, encerra em si processos de reprodução e evolução que garantem a sua continuidade, constituindo causa e consequência de variadas rupturas na coesão social.

Sociologicamente a exclusão é tida como "produto de um défice de coesão social global, não se reduzindo a fenómenos individuais nem a simples agregações de situações" (Rodrigues e outros, 1999).

Uma situação de exclusão define-se pela privação de recursos sociais e materiais, levando para fora da sociedade todos os que não cooperam dos valores e das representações sociais dominantes. O excluído encontra-se à margem dos universos materiais e simbólicos, sofrendo uma rejeição que irá resultar num sentimento de auto-exclusão.

A exclusão, entendida enquanto social, possibilita utilizar a sociedade como contex to de referência à qual se é, ou está excluído (Costa, 1998). 
A exclusão social provoca uma quebra nos laços entre o indivíduo e a sociedade, levando a uma quebra na própria unidade social. Os processos de exclusão traduzem, deste modo, o acumular de deficiências e insucessos em várias esferas sociais, assumindo a forma de uma ruptura dos laços simbólicos (Xiberras, 1996).

Definida deste modo, a exclusão contrapõe-se à noção de cidadania plena, a qual implica e se traduz no acesso a um conjunto de sistemas sociais básicos (Costa, 1998).

A exclusão encontra-se ligada a várias rupturas, pode-se então considerar que a exclusão é:

- Não Ter. Desintegração do sistema de actividade e acesso ao rendimento (devido ao crescente desemprego e terciarização da actividade económica).

- Não Ser. Desintegração social (quebra dos laços de solidariedade e sentido de pertença).

- Não Estar. Desintegração das relações sociais e familiares (com o aparecimento dos novos tipos de estruturas familiares -famílias monoparentais-aumenta a quebra das redes de solidariedade entre as comunidades).

- Não Saber. Desintegração no que se refere ao acesso à educação e às novas tecnologias (o acesso, e direito, à formação e à informação).

- Não Poder. A escassez de recursos a vários níveis (económico, social e cultural).

- Não Participar. Um indivíduo privado de um, ou mais, domínios do sistema social não pode ser visto enquanto cidadão pleno.

Verifica-se assim que nem todas as situações de exclusão social estão associadas aos mesmos handicaps, por isso pode-se falar em tipos de exclusão social (Costa, 1998):

- exclusão económica: privação múltipla por falta de recursos;

- exclusão social: privação relacional caracterizada pelo isolamento, pela não participação;

- exclusão cultural: privação acentuada pelas diferenças de valores entre os grupos que compõem as sociedades.

Existem assim grupos e pessoas excluídos:

- São os que não partilham nem participam na vida social, da família ao emprego, da comunidade à associação.

- São os que não atingem ou não se adaptam aos padrões sociais mínimos, sempre em desenvolvimento de complexidade e exigência.

- São os desenraizados sem passado e sem futuro. 
- São os que não possuem o mínimo cultural vital, entendendo-se este não só como um conjunto de conhecimentos básicos, mas o sentimento de pertença a uma rede social, com direitos e obrigações.

Actualmente, devido às várias mudanças que se desenrolaram na sociedade, surgem novas categorias sociais desfavorecidas que incluem:

- desempregados de longa duração (cujas baixas qualificações dificultam a reinserção no mercado de trabalho);

- grupos étnicos e culturais minoritários (associados à precariedade das condições de vida);

- famílias monoparentais (privação de recursos económicos), pessoas com deficiências (acentuada dependência social e familiar);

- jovens em risco (toxicodependentes excluídos das principais instituições sociais);

- sem abrigo e trabalhadores da economia informal (emprego precário propenso à pobreza e exclusão social);

- jovens à procura do primeiro emprego (principalmente os que não possuem qualificações);

- indivíduos com doenças crónicas (cuja debilidade dificulta o exercício de uma profissão);

- pessoas em situação de dependência (pessoas deficientes, processos decorrentes da longevidade).

\subsection{Situação portuguesa face à pobreza e exclusão social.}

Portugal em termos de modernização sofre de um atraso em relação aos outros Estados europeus. Estando nós na era da globalização em que se verifica que as multinacionais sobrevivem à custa de mão-deobra barata, implantando-se estas em países "ditos de terceiro mundo" e fazendo com que os ricos fiquem cada vez mais ricos e os pobres cada vez mais pobres, verificamos que em Portugal nunca se movimentou tanto dinheiro como nas últimas duas décadas, onde o factor principal que fez com que isto acontecesse foi a abertura das "portas do crédito".

A par desta situação Portugal mantinha um sistema de protecção social deficitário, que não respondia às necessidades, como competia a um verdadeiro Estado-Providência mantendo, assim, baixos níveis de desempenho se compararmos com outros Estados do continente europeu.

Tudo isto deu origem a que fenómenos como a pobreza e a exclusão 
social se intensificassem, e consequentemente o Estado Português, já membro da Comunidade Económica Europeia, começa, na década de 90, a dar prioridade a políticas sociais mais complexas de modo a poder combatê-los.

No entanto as características da pobreza em Portugal têm sofrido alterações, em consequência do desenvolvimento e mudanças da própria sociedade dos últimos anos, o que levou a uma aproximação das características do fenómeno às observadas nas sociedades europeias.

\subsection{Quem são os pobres em Portugal?}

Actualmente, Portugal atravessa uma lenta mas progressiva transição da velha pobreza, para um fenómeno de exclusão social de contornos estruturalmente diferentes.

Em ordem de grandeza dizemos que a taxa de pobreza em Portugal rondará os 20\% (Relatório da EU), o que quer dizer que em cada 5 portugueses 1 é pobre.

Cerca de $1 / 3$ desses pobres serão famílias de reformados, ou melhor de pensionistas. Uma outra área importante da pobreza é a de famílias pobres de pessoas empregadas, estima-se em cerca de $35 \%$ a $38 \%$. Entende-se empregado por conta própria e empregado por conta de outrém. É na categoria de empregado por conta de outrém que se encontra maior percentagem de pobres.

O que quer dizer que há pobres que o são por razões de insuficiência de pensões. E há pobres devido a insuficiência de salários. Depois há também outros pequenos grupos muito diferenciados e com menos peso no número de pobres em Portugal, como sejam: os imigrantes africanos e do Leste europeu, as pessoas com deficiência e as crianças e jovens em risco.

\section{POBREZA E VIOLÊNCIA?}

Ao consultar o dicionário, a violência é definida como: opressão; tirania; aquilo que demanda muita força ou que faz exaurir as forças; constrangimento exercido sobre alguma pessoa para obrigá-la a praticar ou deixar praticar um acto qualquer; coacção.

A violência pode ser encarada enquanto um fenómeno em permanente transformação, fruto de processos de construção social que, em cada momento, traduzem as condições políticas e sociais, mas também as condições de produção discursiva dominantes nessa sociedade, condições essas que tendem a originar em alguns indivíduos ou grupos comportamentos desviantes. 


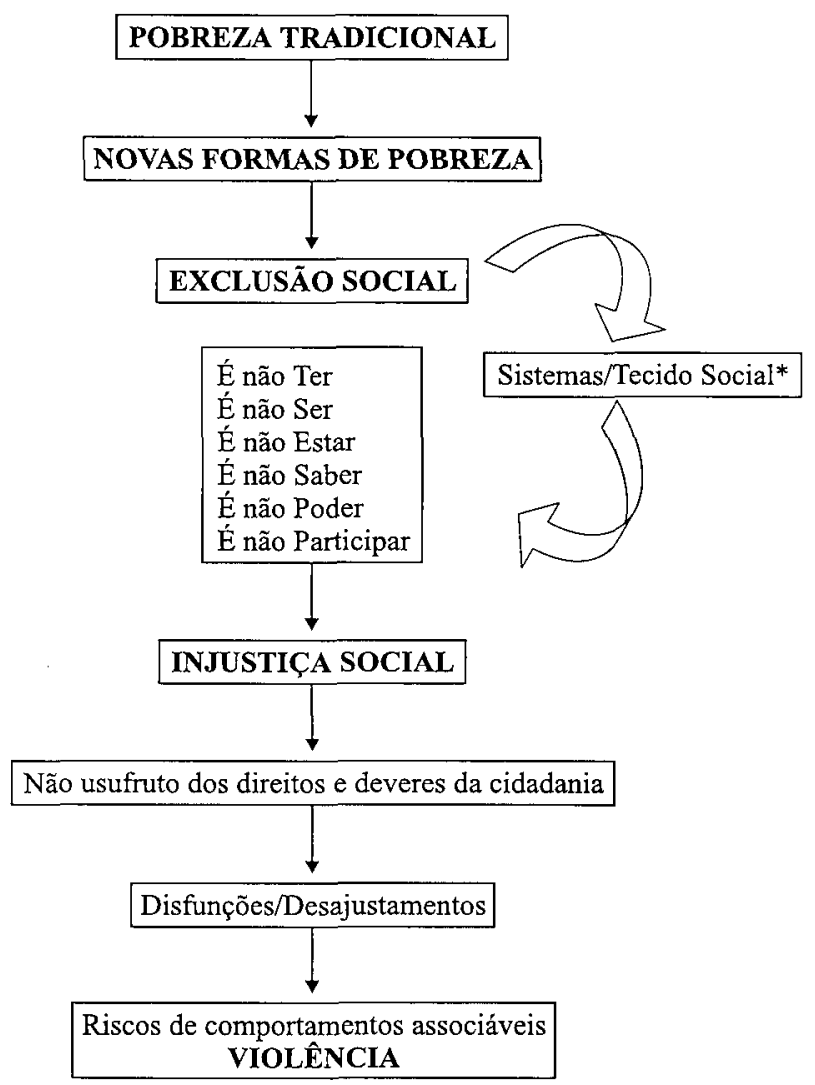

* Está instalado no tecido social e económico mecanismos que excluem pessoas e territórios do acesso aos bens e da participação na sociedade.

Este fenómeno contextualizado na problemática da pobreza e exclusão, irá surgir como uma forma de resposta ao estigma do qual são alvo. De facto, os grupos vulneráveis encontram-se sob pressão pois não têm acesso aos bens e rendimentos, os quais são distribuídos sem obedecer a algum critério de equidade.

No que respeita à junção dos fenómenos pobreza e violência, podemos associar a vertente subjectiva do primeiro conceito, a qual se refere ao juízo que os indivíduos fazem da sua condição, estabelecendo relação entre as necessidades e aspirações comparando-as com os outros ou com a sociedade. Quer isto dizer que a consciência da sua condição pode provocar revolta, gerando "violência", isto é comportamentos associáveis face à sociedade que os exclui.

Os "pobres e excluídos" podem tender a organizar-se, desenvolvendo 
processos geradores de violência, como resposta. São indivíduos que não se encontram em conformidade com os modelos da sociedade actual, o que leva à ideia de que a exclusão e pobreza provocam uma reacção pela negativa (a não consideração das necessidades básicas; as desiguais condições de acesso acarretam o não rompimento com o ciclo da pobreza; privação cria a necessidade de encontrar alternativas pela violência).

Para melhor percepção da violência associada aos contextos de pobreza e exclusão, os contributos de Durkheim (Almeida e outros, 1994) e Merton (Ferreira e outros, 1995) serão de grande importância. Dentro das suas lógicas de pensamento iremos então equacionar esta problemática.

Um dos conceitos abordados por Durkheim é o de anomia, o qual surge quando se verifica a quebra do laço social (desconfiança, rejeição, ódio).

Importa definir anomia como sendo a desagregação dos valores e ausência de referências acompanhadas de desafeição e falta de adesão aos valores.

Como já foi analisado em pontos anteriores, a globalização meramente economicista, o crescimento económico e os avanços tecnológicos deram origem a novas formas de estrutura social, mantendo alguns grupos afastados do pleno exercício de cidadania. Deve também ser abordada a questão relacionada com a constante mutação de valores que se vem verificando, quer em termos da sociedade global, quer em termos da família.

A desregulamentação da vida social levou ao exacerbamento de ideais extremistas (terrorismo é um dos exemplos mais extremados) para contrapor a uma quebra de valores que levava o indivíduo a "andar à deriva".

Sendo o homem um "animal racional" calcula os fins e os meios para obter o que pretende. Assim se verifica com os excluídos, os quais, tendo em conta os objectivos (ruptura com o ciclo da pobreza) enceta estratégias para atingir os fins.

No que respeita à responsabilidade social da violência, ela traduzse na opressão que é infligida pelos sistemas aos indivíduos e grupos, quando não lhe são dadas as oportunidades de acesso aos direitos.

Desta forma, o facto da sociedade não criar oportunidades de acesso de todos aos direitos sociais pode interferir no exercício dos próprios direitos cívicos, até políticos, em que o ser e o estar dos cidadãos são afectados, logo a própria sociedade e sistemas exercem um certo tipo de violência, entendida como opressão sobre os indivíduos e grupos.

Este facto constitui um desrespeito pelas pessoas, seus princípios e 
valores através, quer de acções que agridem a dignidade do ser e das suas condições de vida, quer de omissões devidas à indiferença, ao esquecimento ao qual estas populações estão sujeitas.

\subsection{Modernidade versus violência.}

O capitalismo criou oportunidades de desenvolvimento de processos de industrialização e urbanização. O crescimento económico e demográfico nas cidades levou a situações de segregação social, marginalidade, exclusão e violência.

Assim, o desvio surge como uma resposta à expansão e diferenciação dos processos de socialização dos indivíduos. $O$ facto de se verificar uma instabilidade laboral, acarreta dificuldades de sobrevivência, o que poderá levar, ou não, a formas de comportamentos desviantes.

Há indivíduos e grupos que, sendo alvo de baixas qualificações resultantes de insucesso escolar, encontram entraves no mercado laboral. Isto porque as ocupações a que têm acesso são o trabalho precário e mal remunerado, o que dificulta o aumento de rendimentos para participar no mercado de consumo. Estando em desiguais condições de acesso a determinados bens acabam por ser alvo de exclusão, quer ao nível económico, quer ao nível político e social, uma vez que não participam enquanto membros de pleno direito da sociedade.

Reportando-nos ao caso extremo, fortemente evidenciado pelos acontecimentos de 11 de Setembro de 2001 (ataques terroristas nos EUA), sendo os países muçulmanos (neste caso Afeganistão) flagelados por altos índices de pobreza e também de exclusão (por questões ideológicas e políticas) constatam-se perdas em termos se ser e estar com dignidade, as quais são facilitadores de implementar violência contra os que, por acções e omissões, o colocam à margem do desenvolvimento global.

Ora se encararmos estas atitudes em termos de desvio, torna-se visível que este não advém de um enfraquecimento da regulação social mas sim da constatação de existência contraditória entre os ideais instigados pela cultura moderna (o ocidente) e as oportunidades de satisfação que a própria estrutura social oferece aos indivíduos. Isto porque se as aspirações são para todos, as oportunidades são-no só para alguns. Assim, no momento em que as expectativas culturalmente legitimas não são satisfeitas, os indivíduos enveredarão pelo desvio.

Este esquema mostra como se podem articular os fenómenos pobreza, exclusão e violência, sendo o conflito e consequente desvio, fenómenos explicativos da lógica de funcionamento das disfunções que geram violência. 


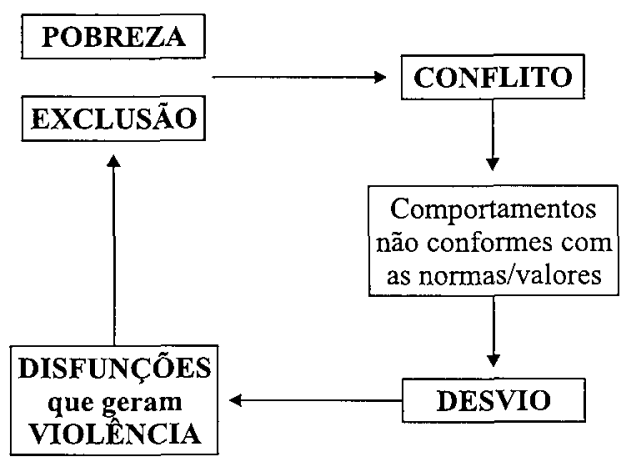

Apesar de esta apresentação se verificar num sentido, o inverso também se pode esperar, pois há uma relação de causa/efeito entre os três fenómenos.

\subsection{A violência enquanto geradora de exclusão e pobreza.}

A violência a que vimos assistindo como resultado de pobreza e exclusão é devido às perdas de sentido de vida, ao desenraísamento, às ausências de afectos, à ignorância, às vulnerabilidades físicas, mentais, psicológicas e às manipulações fáceis e interesseiras.

A violência instala-se quando o ser humano não é tratado como tal -com dignidade, respeito e justiça.

No seguimento deste pensamento podemos verificar a existência de contextos físicos e ambientais carregados de violência, agressores dos direitos essenciais:

- os bairros sociais desumanizados;

- as crianças mal sucedidas, sucessivamente;

- os abandonos físicos e psicológicos;

- a luta pela sobrevivência dos bens essenciais;

- o isolamento e a falta constante de oportunidades e o esquecimento;

- a desigualdade no tratamento;

A violência acontece na escola, no bairro, na família, enfim, na sociedade e no mundo.

A violência é a Galera dos desesperados.

A violência é afinal a procura de alternativas pela negativa. É no entanto uma energia que importa canalizar, canalizar positivamente. 


\subsection{Podemos então falar de segregação/inserção enquanto} facilitadores de existência de actos violentos/não violentos?

Muito embora as políticas sociais desenvolvam uma luta contra a segregação/exclusão e tenham como fim último incluir/integrar todos os indivíduos na sociedade, há determinadas questões que continuam a não ser tidas em conta. Estas omissões potenciam a negação de valores dominantes e acaba por não quebrar o ciclo de pobreza dos marginalizados.

Face a isto, verifica-se a necessidade de canalização de actos violentos de uma forma positiva, no sentido de constituir algo que possa facilitar a integração e o pleno gozo dos direitos.

Chegamos a um outro vértice nesta problematização, a questão das estratégias. De facto é através destas que podemos, quer enquanto sociedade, quer enquanto indivíduos, solucionar a crescente violência nos nossos quotidianos.

A falta ou ausência de alternativas provoca sofrimento nos mais desfavorecidos, sendo que estes podem reagir desajustadamente, o que por sua vez os torna mais vulneráveis impossibilitando a estes uma melhoria da condições de vida actuais.

Ora os actos violentos são disfunções que se verificam em todos os campos da sociedade e criam a necessidade de seguir por um caminho que dê respostas.

Em termos de comunidades, trata-se de apropriação de bens que lhes são negados. O acto do furto é disso um exemplo cabal, independentemente de este se efectivar por este ou por aquele motivo.

A raiz da violência é sempre a mesma: a procura (pela fuga) de alternativas dos desesperados.

Os actos de violência são um espelho da sociedade moderna e reflectem a crise de valores actual. O desrespeito e a não dignificação do ser humano criam barreiras para a inclusão dos mais desprotegidos social e economicamente, e criam desigualdades intoleráveis.

"A negação dos Direitos Humanos e liberdades fundamentais não constitui apenas uma tragédia pessoal, origina também condições de instabilidade política e social, lançando as sementes da violência e do conflito entre sociedades e nações e no seio das mesmas. Tal como diz a primeira frase da declaração universal dos direitos do homem, o respeito pelos direitos humanos e pela dignidade humana «constitui o fundamento da liberdade, da justiça e da paz no mundo» ". (Direitos humanos e serviço social; 22). 


\section{UMA POLÍTICA DE IGUALDADE PARA CONTRAPÔR À VIOLÊNCIA DA EXCLUSÃO.}

Como inverter este processo que, de desigualdades sociais passámos a falar de pobreza, de pobreza passámos a utilizar a expressão exclusão social, estando a assistir hoje à emergência de novas e diversificadas desigualdades, já denominadas "dinâmicas" com contornos novos de comportamentos desadaptados e violência?

Contrapomos a este processo o debate e aprofundamento do princípio de Igualdade. Concretamente definir os parâmetros da promoção de Igualdade supõe assumir como imperativo social a criação de condições que permitam inflectir o determinismo das condições de precaridade social, económica e cultural que afectam indivíduos, famílias ou grupos.

Igualdade, no respeito pelas diferenças é um projecto, um princípio que estrutura o devir de uma sociedade, implicando acção permanente, projecção para o futuro, exercício de solidariedade voluntariamente consentidas.

Concretamente, por outras palavras, promover a Igualdade implica actuar sobre os mecanismos que multiplicam as trajectórias individuais que, da vulnerabilização conduzem à exclusão.

O principio de Igualdade é incompatível com o abandono dos indivíduos ao determinismo dos fenómenos de pauperização e de desfavorecimento conducentes à quebra de laços sociais, à impossibilidade de exercício dos direitos de cidadania e à exclusão dos direitos

\subsection{O que fazer então?}

Fitoussi e Rosavallon numa obra recente defendem a necessidade de avançar uma nova política de identidade. “... Uma política clássica dos direitos do Homem não é suficiente. É preciso desenvolver uma 'política do mundo do privado' que tenha em conta toda a intensidade antropológica das novas formas de sofrimento.

Num espaço em que os laços são tendencialmente mais frágeis, sejam eles laborais ou genealógicos, a prioridade é a reinserção do indivíduo no social e no colectivo." O domínio especifico da política amplifica-se, não para exercer mais controle, mas para produzir condições favoráveis e necessárias à construção e preservação da identidade dos espaços, condicionante da própria identidade dos que neles vivem e neles encontram um lugar e um sentido.

É lugar comum referir a necessidade de definir, construir novas 
políticas, novas formas de articular o social e o económico; o local, o regional, o nacional, o global.

Alguns autores referem ser preciso inventar uma política da experiência que parta do quotidiano dos cidadãos para a formulação das reformas. Em suma uma política que tenha em mente a diversidade e a diferença, que se preocupe com a construção dos laços sociais essenciais à consolidação da coesão social, que remeta a sua acção para a cidadania correcta.

Desafio político, sem dúvida, amplo e exigente na participação de todos os actores sociais.

Política da experiência assente na prática do quotidiano, tentativa de resposta à situação paradoxal do mundo contemporâneo, no qual, e citando Albert Jacquard, "Somos uma humanidade globalmente integrada e localmente deslocada. Globalmente integrada porque os efeitos de uma acção num determinado ponto do planeta tem repercussões no destino de todos-interdependência reforçada pela difusão instantânea da informação, a qual insere cada um numa rede perante a qual é passivo, conferindo um poder inaudito aos que dominam as suas fontes.

Localmente deslocada devido a essa mesma inserção numa rede planetária de malha apertada. A pertença a uma nação, cultura, classe social, tende a não ser mais fortemente sentida. As solidariedades induzidas pelas pertenças desmoronam-se."

É pois a dimensão humana, de cada pessoa, de cada grupo, a sua identidade que está em risco. Risco também de vazio entre os homens, risco que é preciso enfrentar corajosa e decididamente, evitando o deslize perigoso e inaceitável para uma sociedade abstracta, virtual, por absurdo.

A sociedade concreta, real, é a sociedade onde a identidade é possível, em que os Homens são os actores, os motores de um projecto comum.

\subsection{Que fazer com os nossos excluídos?}

As medidas activas para a inserção decorrentes da emergência de uma nova geração das políticas sociais, assentam em alguns dos pressupostos atrás enunciados.

Importa salientar a importância do Rendimento Mínimo Garantido, dos Projectos de Luta Contra a Pobreza, bem como de outros projectos de desenvolvimento comunitário ou de programas cuja lógica de implementação se inscreve numa filosofia de desenvolvimento local.

Ou seja, as decisões tomadas apontam claramente para a 
necessidade de territorializar as políticas sociais, considerando ser este o passo avançado na luta contra a exclusão e futuras formas de violência. $E$ isto porque, encontrar soluções que contribuam para a inclusão dos excluídos, é indissociável do desenvolvimento social, económico e cultural de um determinado território. Por outras palavras, há excluídos porque faltam condições e oportunidades para a inserção, as quais se constroem no território concreto e vivido com as comunidades.

Inventar uma politica de Identidade e da Experiência é investir na recriação dos espaços e das relações utilizando todo o capital do conhecimento e do saber não apenas no sentido do ter mais mas sobretudo no sentido do ser mais.

\section{BIBLIOGRAFIA.}

ALMEIDA, J.F. de; MACHADO, F.L.; CAPUCHA, L.; COSTA, A.F. da; NICOLAU, I.; REIS, E.: "Exclusão Social - Factores e Tipos de Pobreza em Portugal". Celta Editora, 1994.

ALMEIDA, J.F. de; MACHADO, F.L.; CAPUCHA, L.; TORRES, A.C.: "Introdução à Sociologia". Universidade Aberta, 1994.

CAPUCHA, L.: "Pobreza, Exclusão Social e Marginalidades" in "Portugal, que Modernidade?". Celta Editora, 1998.

COSTA, A.B. da: "Exclusões Sociais". Colecção Fundação Mário Soares. Edição Gradiva, 1998.

COSTA, A.B. da; SILVA, M.; PEREIRINHA, J.; MATOS, M.: "A Pobreza em Portugal". Colecção Cáritas, n. ${ }^{\circ}$ 6, 1985.

FERREIRA, J.M.C.; PEIXOTO, J.; CARVALHO, A.S.; RAPOSO, R.; GRAÇA, J.C.; MARQUES, R.: "Sociologia"; McGraw-Hill, Lisboa, 1995.

FITOUSSI, J.-P.; "Debate Tabu: Moeda, Europa, Pobreza". Terramar, 1995.

RODRIGUES, E.V.; SAMAGAIO, F.; FERREIRA, H.; MENDES, M.M.; JANUÁRIO, S.: "A Pobreza e a Exclusão Social: Teorias, Conceitos e Políticas Sociais em Portugal" in "Sociologia". Faculdade de Letras. Porto, 1999.

XIBERRAS, M.: "As Teorias da Exclusão - Para Uma Construção do Imaginário do Desvio". Instituto Piaget, 1996.

\section{OUTRAS PUBLICAÇÕES:}

MINISTÉRIO DO TRABALHO EDA SOLIDARIEDADE: "Plano Nacional de Acção para a Inclusão - Compromisso com a Inclusão, Compromisso para a Inclusão, Portugal 2001-2003", Junho 2001. 
ORGANIZAÇÃO DAS NAÇÕES UNIDAS: "Direitos Humanos e Serviço Social: Manuela para Escolas e Profissionais de Serviço Social". ISSS Departamento Editorial, 1999.

ORGANIZAÇÃO DAS NAÇÕES UNIDAS: "Relatório do Desenvolvimento Humano 2001". Retirado do site www.undp.org/hdr2001

RITA, J.J.P.: "Prevenir e combater a exclusão social estruturando o desenvolvimento das regiões: um espaço para a sociedade civil?", Intervenção Social. ISSS - Departamento Editorial. Lisboa 1999. Número 19; págs 87-110. 